DIAS, L.R.O. et al. Doenças parasitárias reprodutivas em bovinos - Neosporose. PUBVET, Londrina, V. 8, N. 3, Ed. 252, Art. 1671, Fevereiro, 2014.

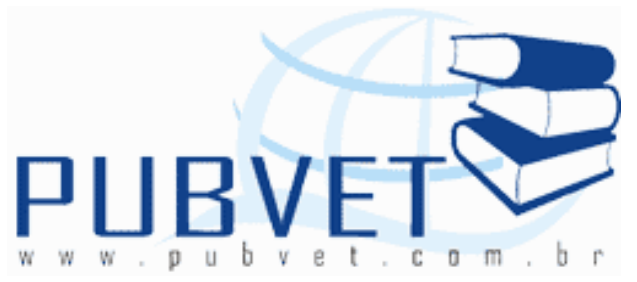

PUBVET, Publicações em Medicina Veterinária e Zootecnia.

\title{
Doenças parasitárias reprodutivas em bovinos - Neosporose
}

Luzia Renata Oliveira Dias ${ }^{1}$, Henrique Trevizoli Ferraz ${ }^{2}$, Marco Antônio de Oliveira Viu², Dyomar Toledo Lopes², Alessandra Feijó Marcondes Viu²

1 Médica Veterinária Residente do Laboratório de Fisiopatologia da Reprodução Animal, UFG/CAJ. e-mail: Ir_dias@hotmail.com

${ }^{2}$ Professores da Universidade Federal de Goiás - Campus Jataí

\section{Resumo}

A neosporose bovina é uma doença infecciosa de expressão global, de origem parasitária, causada pelo protozoário Neospora caninum, que gera grande impacto econômico por causar o aborto em bovinos de corte e de leite em vários países. Apesar de altas prevalências de anticorpos nos animais, a frequência de neosporose clínica tem sido pouco registrada. Para controle efetivo da doença, deve-se coletar e eliminar fetos abortados, membranas fetais, placentas e bezerros natimortos, impedindo assim a ingestão por cães de material contaminado. Esta revisão de literatura propõe-se a abordar aspectos importantes da neosporose bovina, incluindo a etiologia, epidemiologia, patogenia, sintomas, diagnóstico, prognóstico, terapêutica e controle.

Palavras-chave: abortos, cães, Neospora caninum, protozoário, reprodução 
DIAS, L.R.O. et al. Doenças parasitárias reprodutivas em bovinos - Neosporose. PUBVET, Londrina, V. 8, N. 3, Ed. 252, Art. 1671, Fevereiro, 2014.

\title{
Reproductive parasitic diseases in cattle - Neosporosis
}

\begin{abstract}
The bovine neosporosis is an infectious disease of global expression, of parasitic origin, caused by the protozoan Neospora caninum, which generates great economic impact to cause abortion in beef cattle and milk in several countries. Despite the high prevalence of antibodies in animals, the frequency of clinical neosporosis has been poorly recorded. For effective control of the disease, we must collect and remove aborted fetuses, fetal membranes, placenta and dead calves, avoiding the ingestion by dogs of contaminated material. This review aims to highlight important aspects of bovine neosporosis, including etiology, epidemiology, pathogenesis, symptoms, diagnosis, prognosis, treatment and control.
\end{abstract}

Keywords: abortions, dogs, Neospora caninum, protozoan, reproduction

\section{INTRODUÇÃO}

De acordo com DUBEY \& LINDSAY (1996), a neosporose bovina é uma doença infecciosa de expressão mundial e de origem parasitária, causada pelo protozoário Neospora caninum, possuindo grande importância econômica devido ao fato de causar abortos nas fêmeas bovinas em diversos países. Ainda segundo estes autores, a doença foi diagnosticada pela primeira vez em 1988, quando foi isolado o agente em filhotes de cães pela cultura de células com posterior inoculação em camundongos, desenvolvendo-se assim o teste de Imunofluorescência Indireta (IFI) para diagnóstico sorológico.

O parasita pode ser encontrado em vários tecidos das espécies infectadas, principalmente nas células do sistema nervoso. Tais espécies podem ser bovinos, caninos, ovinos, equinos e caprinos (DUBEY \& LINDSAY, 1996). Em estudo realizado por GONDIM (2006), o parasita foi identificado em cervídeos, camelídeos, mustelídeos e canídeos. Em ratos e camundongos a infecção também foi confirmada (HUANG et al., 2004; FERROGLIO et al., 2007; JENKINS et al., 2007). Diferentemente dos estudos que identificaram $N$. 
DIAS, L.R.O. et al. Doenças parasitárias reprodutivas em bovinos - Neosporose. PUBVET, Londrina, V. 8, N. 3, Ed. 252, Art. 1671, Fevereiro, 2014.

caninum somente em mamíferos, COSTA et al. (2008) o detectaram também em galinhas.

Estudos têm procurado identificar os fatores de risco envolvidos na maior frequência de anticorpos anti- $N$. caninum nos rebanhos de corte ou de leite e, dentre eles, se destacam fatores relacionados ao manejo do rebanho (intensivo ou extensivo), a idade dos bovinos e a presença de cães na propriedade (CORBELLINI et al., 2006).

A doença foi diagnosticada pela primeira vez no Brasil em 1997, no estado de São Paulo, através do teste sorológico de IFI (GONDIM et al., 1999; FERREIRA, 2000).

Esta revisão de literatura propõe-se a abordar aspectos importantes da neosporose bovina, incluindo a etiologia, epidemiologia, patogenia, sintomas, diagnóstico, prognóstico, terapêutica e controle.

\section{Etiologia}

O protozoário $N$. caninum pertence ao filo Apicomplexa semelhante ao Toxoplasma gondii, porém com diferenças estruturais e antigênicas (DUBEY et al., 1988), sendo coccídio e intracelular (TAYLOR et al., 2010). As formas encontradas intracelularmente no hospedeiro intermediário (HI) são os taquizoítos, que possuem forma ovoide ou globosa, medindo em torno de $6 \mathrm{X}$ $2 \mu \mathrm{m}$ que podem ser encontrados no citoplasma da célula, dentro ou fora do vacúolo parasitófago. Já os cistos possuem forma oval e parede lisa, podem medir até $107 \mu \mathrm{m}$ de diâmetro, sendo encontrados nas células do sistema nervoso. No interior dos cistos estão presentes os bradizoítos medindo em torno de $7 \times 1,5 \mu \mathrm{m}$ de comprimento. Esse parasita tem um ciclo de vida heteróxeno (o ciclo só é completado quando possuem dois ou mais hospedeiros) com estágio sexual ocorrendo no intestino do hospedeiro definitivo (HD), podendo ser transmitido por meio das fezes (McALLISTER et al., 1998; ANDREOTTI, 2001; GUIMARÃES JÚNIOR \& ROMANELLI, 2006).

MCALLISTER et al. (1998) foram os primeiros a descrever o ciclo biológico deste parasita, o qual envolve HI's e HD's. O cão e o coiote são os 
DIAS, L.R.O. et al. Doenças parasitárias reprodutivas em bovinos - Neosporose. PUBVET, Londrina, V. 8, N. 3, Ed. 252, Art. 1671, Fevereiro, 2014.

HD's do $N$. caninum, os quais eliminam os oocistos após a ingestão de tecidos ou órgãos de seus HI's (membranas placentárias contaminadas com cistos), sendo estes os bovinos, caprinos, ovinos, equinos e cervídeos que se infectam pela ingestão de oocistos contaminando o ambiente (BARR, 1998).

No HD há uma fase sexuada, já no HI a fase é assexuada, sendo que segundo MUGRIDGE et al. (1999), é dada pelo processo de endopoligenia (formação de mais de duas células filhas). O HD é infectado ao consumir alimentos contaminados com parasitas na forma cística oriundos de HI's (como por exemplo, vísceras de bovinos). Em seguida ocorre a fase sexuada no HD, com sua multiplicação no intestino e liberação dos oocistos nas fezes. O HI se infecta ingerindo alimentos contaminados com fezes contendo oocistos esporulados. No estômago do HI, os oocistos rompem-se pela ação mecânica liberando os esporozoítos, que invadem os tecidos e sofrem multiplicação assexuada originando taquizoítos móveis, que são encontrados em desenvolvimento dentro de vacúolos parasitófagos (cistos teciduais) de várias células como neurônios, macrófagos, fibroblastos e miócitos (COLLERY, 1996). Este ciclo biológico está representado na Figura 1.

O ciclo é restabelecido quando cistos contendo bradizoítos são consumidos por um HD, os quais são encontrados em tecidos nervosos periféricos e centrais, podendo ficar em latência por meses ou anos (DUBEY \& LINDSAY, 1996).

\section{Epidemiologia}

No Brasil índices variáveis de soropositividade têm sido encontrados em diversos estudos, geralmente em propriedades leiteiras e com problemas reprodutivos (VOGEL et al., 2006).

GONDIM et al. (1999) realizaram um dos primeiros estudos de soroprevalência do $N$. caninum em bovinos. Neste estudo avaliou-se soro sanguíneo de 447 vacas das raças Holandesa e Mestiça, em 14 propriedades leiteiras do estado da Bahia, sendo que $80 \%$ dos animais estavam em lactação. Os resultados obtidos mostraram a detecção de anticorpos em 63 
DIAS, L.R.O. et al. Doenças parasitárias reprodutivas em bovinos - Neosporose. PUBVET, Londrina, V. 8, N. 3, Ed. 252, Art. 1671, Fevereiro, 2014.

$(14,09 \%)$ dos 447 animais testados. OGAWA (2000) coletou 385 amostras de soro de bovinos leiteiros da região norte do estado do Paraná e observaram um percentual de $11,69 \%$ de soropositividade para o $N$. caninum, não ocorrendo reação cruzada com o T. gondii. Ainda no Paraná, na região Sudoeste, CAMILLO et al. (2010) realizaram um levantamento sorológico a partir de 1778 amostras de soro de fêmeas bovinas, testadas pela reação de inumofluorescência indireta (RIFI), tendo ocorrência de 24,2\% de anticorpos anti-N. caninum.

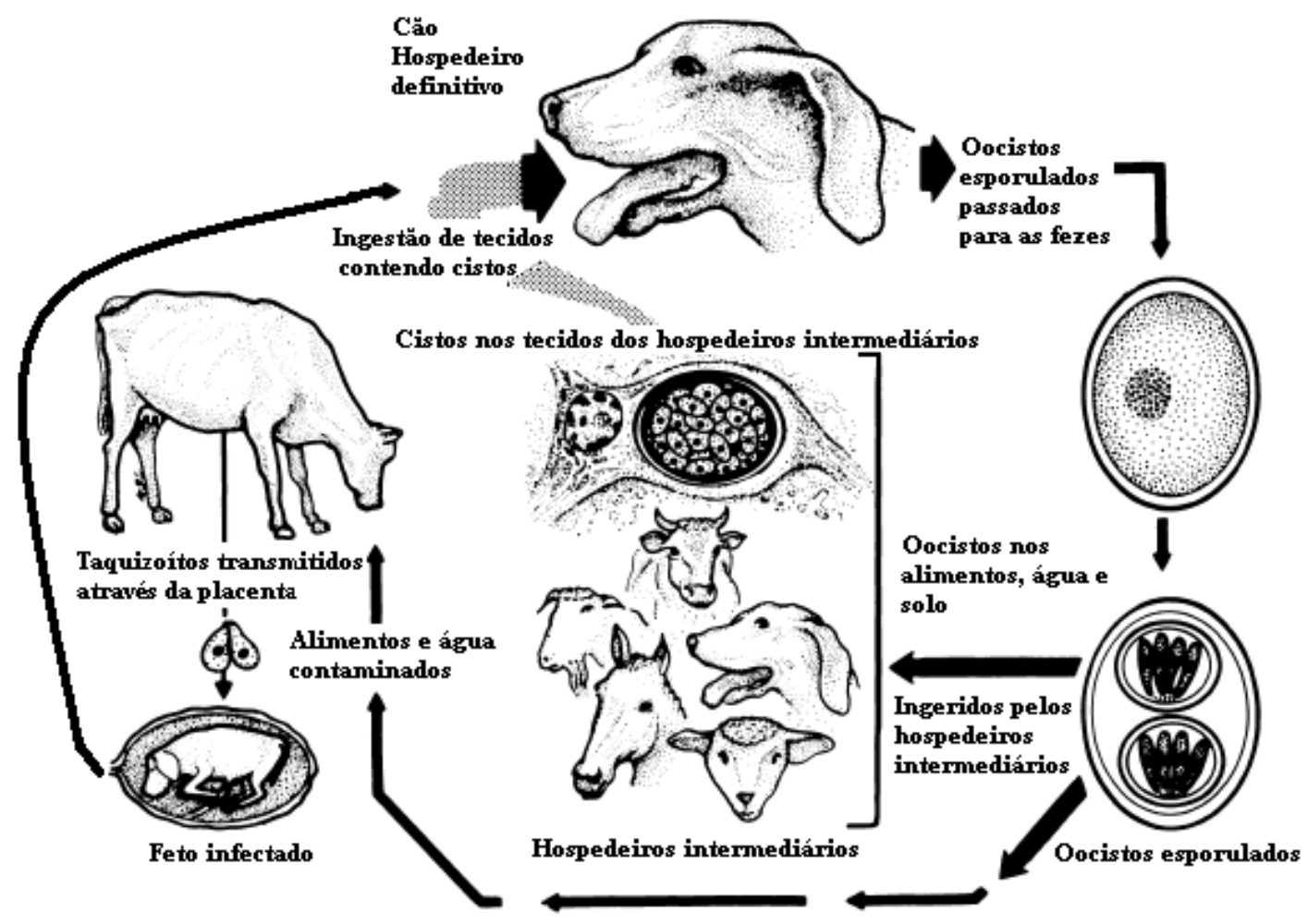

FIGURA 01 - Ciclo biológico do Neospora caninum. Adaptado de DUBEY (1999a). 
DIAS, L.R.O. et al. Doenças parasitárias reprodutivas em bovinos - Neosporose. PUBVET, Londrina, V. 8, N. 3, Ed. 252, Art. 1671, Fevereiro, 2014.

Em um levantamento realizado em seis estados brasileiros sobre a ocorrência de anticorpos para $N$. caninum em soros bovinos, indicou-se soropositividade de $23,6 \%$, com relativo aumento nos índices em animais com idade superior a 24 meses. Dentre estes Estados, Minas Gerais apresentou maior porcentagem de animais reagentes $(29,0 \%)$ e o Rio de Janeiro apresentou a menor $(14,17 \%)$. A ocorrência em bovinos de leite $(26,2 \%)$ foi maior em relação aos de corte $(19,1 \%)$. Os Estados do Paraná, Mato Grosso do Sul e Rio Grande do Sul apresentaram maior incidência em bovinos de corte e Minas Gerais nos de leite (RAGOZO et al., 2003).

SARTOR et al. (2005) realizaram estudos no estado de São Paulo, onde demonstraram ocorrência de anticorpos anti- $N$. caninum de 35,54\% para gado leiteiro e 20,0\% para gado de corte.

No estado de Goiás MELO et al. (2006), trabalhando com 21 rebanhos bovinos de leite, corte e misto, criados nas microrregiões de Goiânia e Anápolis, detectaram prevalência de anticorpos anti- $N$. caninum em 30,4\% dos animais investigados, onde todas as propriedades tinham animais positivos, sendo que a prevalência variou entre $10,3 \%$ e $89,7 \%$.

Segundo ALMEIDA (2004), apesar de altas prevalências de anticorpos nos animais, a frequência de neosporose clínica tem sido pouco registrada, provavelmente devido à infecção apresentar sinais clínicos comuns a outras enfermidades reprodutivas, tais como brucelose e leptospirose. De acordo com RADOSTITS et al. (2002), o aborto parece ser o único sinal clínico em vacas infectadas. Segundo FORTUNATO et al. (2010), os abortos podem apresentar padrão epidêmico se $10 \%$ ou mais dos animais em risco abortarem em seis a oito semanas, ou endêmico se mais de $5 \%$ dos animais abortarem durante vários anos. Segundo McALLISTER et al. (2000), surtos epizoóticos ocorrem por infecção primária dos animais, ou como afirma PARKINSON (2009), por exposição dos animais à outro agente infeccioso ou outro fator capaz de causar imunossupressão. 
DIAS, L.R.O. et al. Doenças parasitárias reprodutivas em bovinos - Neosporose. PUBVET, Londrina, V. 8, N. 3, Ed. 252, Art. 1671, Fevereiro, 2014.

\section{Patogenia}

A infecção primária (exógena) da vaca resulta da ingestão de oocistos, que provavelmente se encistam no intestino delgado, liberando esporozoítos. Os esporozoítos então parasitam o epitélio intestinal, transformando-se em taquizoítos e sofrem fase de multiplicação, eventualmente sob os linfonodos mesentéricos e são liberados para o sangue. A parasitemia conduz à disseminação do parasita em todo organismo, incluindo o útero gravídico (DUBEY et al. 2006).

A principal rota de infecção no rebanho é a transmissão vertical (transplacentária) nos bovinos, tendo eficiência de até 95\% (GUIMARÃES, 2007). Essa transmissão é responsável pela persistência do $N$. caninum no rebanho, devido à propagação da infecção para sucessivas gerações e em prenhezes consecutivas (DUBEY, 2003; GUIMARÃES, 2007).

Horizontalmente, os animais também podem se infectar pela ingestão de oocistos eliminados nas fezes do cão. Esta via parece ser necessária para a manutenção e introdução de novas infecções no rebanho. Além disso, estudos têm sugerido a transmissão lactogênica (via colostro) (HALL et al., 2005; GUIMARÃES, 2007; MOSKWA et al., 2007). SERRANO-MARTINEZ et al. (2007) também demonstraram a indução da infecção em vacas inseminadas com sêmen bovino contaminado experimentalmente com taquizoítos do parasita.

A probabilidade de vacas soropositivas abortarem é maior do que aquelas que são soronegativas (DAVISON et al., 1999). Estas observações sugerem reativação de uma infecção persistente estabelecida, possivelmente desencadeada pela baixa regulação da imunidade celular mediada que ocorre em meados da gestação (INNES et al., 2005). A evidência indica que em animais persistentemente infectados o parasita é confinado para o sistema nervoso central (SNC) e músculo esquelético, na forma de bradizoítos dentro de cistos nos tecidos onde está em equilíbrio com a barreira do sistema imune (DUBEY et al., 2006).

O N. caninum é controlado em grande parte por imunidade celular mediada por mecanismos de linfócitos $T$ citotóxicos propensos a ter um papel 
DIAS, L.R.O. et al. Doenças parasitárias reprodutivas em bovinos - Neosporose. PUBVET, Londrina, V. 8, N. 3, Ed. 252, Art. 1671, Fevereiro, 2014.

protetor significativo, demonstrável pela morte de autólogos do parasita (STASKA et al., 2003). Este grau de proteção é realizado na fase inicial da gestação. No entanto, na metade da gestação a imunidade parece ser modificada. Ensaios in vitro mostraram baixa regulação de respostas celulares ao mitógeno, redução na proliferação celular em resposta específica para antígeno e redução na produção de interferon-gama (IFN- $\gamma$ ), sugerindo que a gestação permite a reativação de cistos do parasita que levam à liberação de bradizoítos nos tecidos (DUBEY et al., 2006).

Após a parasitemia, o parasita é capaz de estabelecer-se nas carúnculas do septo maternal antes de atingir as vilosidades da placenta fetal (MALEY et al., 2003; MACALDOWIE et al., 2004). Para que o aborto ocorra, o feto ou a placenta têm que estar danificados até que estejam inviáveis, sendo que vários fatores podem interagir para influenciar este processo. A indução placentária pelo parasita pode colocar em risco a sobrevivência do feto diretamente, ou causar a liberação de prostaglandinas maternas, que por sua vez causam luteólise e aborto. O dano fetal pode ocorrer devido a danos no tecido primário causados pela multiplicação de $N$. caninum no feto, ou devido à insuficiência de oxigênio/nutrição, secundária à lesão placentária. Além disso, a expulsão imunológica materna do feto pode ocorrer associada com a liberação maternal de citocinas pró-inflamatórias na placenta (DUBEY et al., 2006).

O início da infecção placentária coincide com a entrada do parasita na corrente sanguínea fetal e consequente invasão dos tecidos, com uma predileção pelo SNC. Inicialmente o parasita é localizado em volta dos vasos sanguíneos e, no feto mais jovem, sua multiplicação descontrolada pode causar destruição generalizada letal do neuropil, com pouca ou nenhuma inflamação (DUBEY et al., 2006).

Durante o primeiro trimestre de gestação o feto é particularmente vulnerável à multiplicação da parasitemia, quando o timo, o baço e os nódulos linfáticos periféricos são formados primeiro, mas esses tecidos começam a 
DIAS, L.R.O. et al. Doenças parasitárias reprodutivas em bovinos - Neosporose. PUBVET, Londrina, V. 8, N. 3, Ed. 252, Art. 1671, Fevereiro, 2014.

reconhecer e responder a micro-organismos somente no terço médio de gestação (OSBURN, 1986).

\section{Sinais Clínicos}

O abortamento é o sinal clínico mais evidente da infecção. Portanto, se a infecção intrauterina ocorrer no início da gestação, antes do desenvolvimento do sistema imune fetal, esta causará morte embrionária. A infecção no meio da gestação resultará em abortamento ou nascimento de um bezerro persistentemente infectado. Se ocorrer no período final da gestação, acontecerá o parto normalmente, porém o bezerro pode ser congenitamente infectado, podendo esta infecção se repetir em gerações futuras (GUIMARÃES, 2007).

Em bovinos, abortos são notados clinicamente a partir do terceiro mês de gestação até próximo ao parto (DUBEY \& LINDSAY, 1996). Entretanto, ANDREOTTI (2001) afirmou que o aborto pode ocorrer em qualquer momento a partir do segundo mês de gestação.

Além da ocorrência de aborto precoce, a doença em vacas de corte é relacionada ao nascimento de bezerros prematuros com peso reduzido. Conforme o grau de prematuridade, esses bezerros podem ser mantidos vivos por meio de monitoramento intensivo durante o período neonatal (RADOSTITS et al., 2002). No entanto, a manutenção destes animais não seria salutar ao rebanho, pois FORTUNATO et al. (2010) ressaltaram que os bezerros nascidos de vacas congenitamente infectadas frequentemente nascem persistentemente infectados. Além disso, estes animais apresentam maior risco de aborto, particularmente na sua primeira gestação. Posteriormente, exibem maior tendência para originar bezerros também congenitamente infectados do que para abortar.

Vacas infectadas apresentam diminuição na produção de leite já na primeira lactação. Os bezerros infectados podem ter o seu peso reduzido ao nascimento, além de apresentarem dificuldade de se levantar e manifestações nervosas. Os membros posteriores podem se apresentar flexionados ou 
DIAS, L.R.O. et al. Doenças parasitárias reprodutivas em bovinos - Neosporose. PUBVET, Londrina, V. 8, N. 3, Ed. 252, Art. 1671, Fevereiro, 2014.

hiperextendidos e, ao exame neurológico, também pode-se notar diminuição do reflexo patelar, ataxia e perda de consciência (FERRE et al., 2003).

As manifestações clínicas variam dependendo da idade do feto, do estágio de desenvolvimento do sistema imune, tempo de exposição ao parasita e distribuição das lesões no SNC (ANDERSON et al., 1997).

Segundo RADOSTITS et al. (2002), o cérebro encontra-se autolisado e deve ser examinado junto com o coração, fígado e placenta. Podem ser encontradas lesões de encefalite multifocal, miocardite e hepatite periportal.

A multiplicação intracelular dos taquizoítos leva à formação de focos de necrose de dimensões variáveis. Lesões necrosantes são circundadas e infiltradas por reação celular inflamatória (composta de células mononucleares) e vasculite (JONES et al., 2000; DUBEY et al., 2006).

As lesões são decorrentes da inflamação necrosante e granulomatosa. No cérebro ocorre meningoencefalite não supurativa das substâncias cinzenta e branca, seguida de gliose e coleções perivasculares de células mononucleares. Além das coleções proliferantes de taquizoítos podem estar presentes cistos de paredes espessas contendo bradizoítos, com frequência em áreas sem necrose ou inflamação significativa (JONES et al., 2000).

Nos fetos abortados a principal lesão é encefalomielite necrosante e não supurativa multifocal, mas a disseminação também pode ocorrer, assim como placentite (JONES et al., 2000; DUBEY et al., 2006).

\section{Diagnóstico}

Segundo PAZ et al. (2007), para se chegar a um possível diagnóstico, a história clínica de problemas reprodutivos no rebanho e sua associação com a pesquisa sorológica são de grande importância. Neste mesmo sentido RADOSTITS et al. (2002) reportaram que o diagnóstico de suspeição baseia-se nas lesões fetais reveladas pela microscopia e soropositividade da mãe, porém o diagnóstico definitivo requer a demonstração do protozoário em tecidos 
DIAS, L.R.O. et al. Doenças parasitárias reprodutivas em bovinos - Neosporose. PUBVET, Londrina, V. 8, N. 3, Ed. 252, Art. 1671, Fevereiro, 2014.

fetais por meio de técnicas imunoistoquímicas de marcação em associação a exames sorológicos dos rebanhos.

Os testes diagnósticos utilizados atualmente são: imunofluorescência IFI, teste imunoenzimático (ELISA) e teste de imuno-histoquímica. Os dois primeiros indicam exposição do animal ao agente, não necessariamente significando que os mesmos se encontram doentes (ANDREOTTI, 2001).

Segundo DUBEY (2003), o exame histológico dos tecidos fetais é a técnica de referência para o diagnóstico em fetos abortados. De acordo com DE MEERSCHAM et al. (2002), quando não for possível enviar o feto inteiro, as amostras a serem remetidas são cérebro, coração, fígado e placenta.

São inúmeros os estudos epidemiológicos de infecção por $N$. caninum realizados por meio de testes sorológicos (HEMPHILL \& GOTTSTEIN, 2000). Contudo, suspeita-se que a identificação de animais soropositivos para $N$. caninum pode ser prejudicada devido à reatividade cruzada com outros protozoários Toxoplasmatíneos, principalmente $N$. hughesi e Hammondia heydorni (GONDIM et al., 2009).

Não há teste sorológico disponível, até o momento, capaz de discriminar anticorpos anti- $N$. caninum de anticorpos anti- $N$. hughesi. É desconhecido o potencial de $N$. hughesi de infectar outras espécies animais, portanto, os inquéritos sorológicos realizados para a detecção de anticorpos anti- $N$. caninum podem, em parte, corresponder a infecções por $N$. hughesi (GONDIM et al., 2009).

Problema semelhante ao descrito no parágrafo anterior pode ocorrer com Hammondia heydorni, parasito filogeneticamente bastante próximo a $N$. caninum, que nunca foi isolado e propagado in vitro (SLAPETA et al., 2002). Por conta disso, não existe teste sorológico para a detecção de anticorpos anti$H$. heydorni. Devido à proximidade filogenética entre $H$. heydorni e $N$. caninum, é possível que esses parasitos tenham um certo número de antígenos comuns, o que pode causar reatividade cruzada nos testes diagnósticos (GONDIM, 2008). 
DIAS, L.R.O. et al. Doenças parasitárias reprodutivas em bovinos - Neosporose. PUBVET, Londrina, V. 8, N. 3, Ed. 252, Art. 1671, Fevereiro, 2014.

Portanto, sabendo-se que os testes sorológicos são utilizados frequentemente para a identificação de animais infectados ou expostos ao parasito, deve-se levar em consideração que tais testes podem estar falhando em detectar animais expostos ao N. caninum (GONDIM, 2008).

Diante do exposto, fica clara a necessidade de identificação do agente. Assim o teste de imuno-histoquímica é indispensável para a demonstração do protozoário nos tecidos. Porém, segundo BASZLER et al. (1999) e DUBEY (1999b) esse teste é pouco sensível para detectar o parasita em tecidos do hospedeiro, devido ao baixo número de parasitas e à baixa qualidade do tecido fetal, que pode estar autolisado, mumificado ou macerado. Sendo assim, o PCR (reação da polimerase em cadeia) tem sido o mais utilizado no diagnóstico de aborto em bovinos em estudos epidemiológicos e filogenéticos, devido à rapidez e facilidade de execução.

Quando o material fetal não está disponível, o diagnóstico presuntivo pode ser conseguido através da detecção de anticorpos por testes sorológicos, os quais são utilizados em estudos e esforços de controle epidemiológico de $N$. caninum (WAPENAAR et al., 2007).

\section{Diagnóstico diferencial}

Segundo ANDREOTTI et al. (2003), para confirmação de infecção por $N$. caninum é necessário diferencia-la de Sarcocystis sp. e de T. gondii, através dos métodos imuno-histoquímico ou por PCR, que podem causar lesões similares em fetos. Além disso, em casos de abortos e morte perinatal, doenças como brucelose, campilobacteriose, tricomoníase, leptospirose, rinotraqueíte viral bovina e diarreia viral bovina, listeriose e aborto viral epizoótico devem ser pesquisadas. Deve-se considerar o período de abortamento, realizar o exame a campo do feto e placenta, além do diagnóstico laboratorial pelo isolamento do agente e também sorologia (RADOSTITS et al., 2002). 
DIAS, L.R.O. et al. Doenças parasitárias reprodutivas em bovinos - Neosporose. PUBVET, Londrina, V. 8, N. 3, Ed. 252, Art. 1671, Fevereiro, 2014.

\section{Terapêutica}

Segundo TAYLOR et al. (2010), não existe tratamento eficaz para neosporose em bovinos. No entanto, RADOSTITS et al. (2002) afirmam que o tratamento estratégico de vacas em gestação com droga antiparasitária adequada pode interromper a infecção, sendo uma medida eficaz em animais de corte, mas não permitido para vacas leiteiras em lactação devido à possibilidade do aparecimento de resíduos no leite.

KRITZNER et al. (2002) realizaram um estudo exploratório para avaliar a eficácia de toltrazuril sulfona em bezerros infectados experimentalmente com $N$. caninum e provaram essa eficácia. No estudo a medicação foi realizada por via oral com $20 \mathrm{mg} / \mathrm{kg}$ de peso corporal, utilizando-se uma suspensão de $5 \%$. A primeira dose foi aplicada 24 horas após a infecção, sendo repetida a cada 24 horas subsequentes, durante seis dias. HAERDI et al. (2006) realizaram estudo onde 36 bezerros foram medicados com toltrazuril, $20 \mathrm{mg}$ por $\mathrm{kg}$ de peso corporal, administrado três vezes, a cada dois dias, dentro de 7 dias post natum; e 36 receberam placebo. Três meses após a medicação, não houve diferença na reatividade de anticorpos entre os dois grupos. No entanto, após 4 a 6 meses, foram encontradas diferenças significativas, o que é explicado por uma forte imunidade humoral após a ação quimioterápica sobre parasitas, enquanto os animais tratados com placebo só responderam fracamente à infecção persistente.

Em estudo realizado por MATOS (2008), foram testados flavonoides (3,4 dihidroxiflavona; $\quad 3^{\prime}, 4^{\prime}, 5^{\prime}, 7-\quad$ tetrahidroxiflavona; $3,3^{\prime}, 4^{\prime}, 5,6$ pentahidroxiflavona) mostrando resultados promissores com relação ao potencial antiparasitário para $N$. caninum, visto que induziram reatividade das células gliais e inibiram a proliferação de cepa 1 do $N$. caninum.

\section{Controle}

Para um controle efetivo da doença deve-se coletar e eliminar fetos abortados, membranas fetais, placentas e bezerros mortos, impedindo a 
DIAS, L.R.O. et al. Doenças parasitárias reprodutivas em bovinos - Neosporose. PUBVET, Londrina, V. 8, N. 3, Ed. 252, Art. 1671, Fevereiro, 2014.

ingestão por cães. Além disso, evitar o acesso destes às fontes de água, pastagens, galpões e silos onde se armazenam alimentos e impedir a entrada de animais positivos no rebanho. Estas medidas reduzem a infecção horizontal na propriedade. A transferência de embriões é uma técnica adequada para reduzir a transmissão vertical, desde que seja realizada em receptoras soronegativas (BAILLARGEON et al., 2001; GUIMARÃES, 2007).

Vacinas mais eficientes e com menor custo de produção podem ser uma alternativa para imunoproteção, sendo este o caso das vacinas recombinantes. Algumas proteínas imunodominantes, presentes em grande quantidade na superfície dos taquizoítos, são descritas como um antígeno potencial para uso no desenvolvimento de uma vacina recombinante (HEMPHILL et al., 1997).

Em estudo realizado por RODRIGUES (2009), avaliando a imunogenicidade da proteína NcSRS2 recombinante presente na superfície dos bradizoítos e taquizoítos de $N$. caninum, três formulações de vacinas recombinantes (NcSRS2 + óleo, NcSRS2 + Xantana e NcSRS2 + Hidróxido de alumínio) foram capazes de induzir uma resposta imune humoral específica, com títulos de IgG1 e IgG2a, demonstrando que as vacinas testadas podem ser importante medida de controle da neosporose.

BARAJAS-ROJAS et al. (2012) realizaram estudo no México para avaliar a eficácia da vacina inativada de $N$. caninum (Bovilis Neoguard ${ }^{\circledR}$ fabricada pela MSD no México), onde 200 vacas leiteiras foram selecionadas aleatoriamente no terceiro mês de prenhez, sendo divididas em dois grupos de 100 animais cada. Um dos grupos recebeu a primeira dose da vacina (grupo vacinado) e o outro grupo não foi vacinado (grupo não-vacinado). Após 30 dias da primeira dose o grupo vacinado recebeu a segunda dose da vacina. Amostras de sangue foram analisadas através do teste indireto de ELISA. Reposta imunológica foi observada no grupo vacinado aos 30 dias e 60 dias após a vacinação. Taxa de abortamento de $12 \%$ foi observada nas vacas do grupo vacinado com idade média de prenhez de 98 dias. No grupo nãovacinado a taxa de abortamento de $29 \%$ apresentou diferença $(P<0,05)$ com 
DIAS, L.R.O. et al. Doenças parasitárias reprodutivas em bovinos - Neosporose. PUBVET, Londrina, V. 8, N. 3, Ed. 252, Art. 1671, Fevereiro, 2014.

idade média de prenhez de 80 dias. A média geral de dias de abortamento para ambos os grupos foi de 89 dias. A diferença na taxa de abortamento entre os grupos vacinado e não-vacinado foi de $41 \%$.

\section{CONSIDERAÇÕES FINAIS}

A neosporose bovina é uma enfermidade de extrema importância, principalmente por causar elevado prejuízo reprodutivo aos rebanhos, gerando grande impacto econômico negativo nos sistemas de produção onde não há controle efetivo dos fatores que resultam na transmissão da doença.

Devem ser tomadas medidas simples como a coleta de materiais potencialmente infectados, como por exemplo, restos de aborto, impedindo a ingestão destes por cães, visando diminuir os riscos de transmissão. Além de se evitar a presença de cães em locais de criação de bovinos.

A implementação de um programa de vacinação pode resultar de forma considerável na minimização dos prejuízos econômicos causados pelo abortamento, uma vez que produz resposta sorológica significante em vacas vacinadas.

\section{REFERÊNCIAS}

ALMEIDA, M. A. O. Epidemiologia de Neospora caninum. Revista Brasileira de Parasitologia Veterinária, São Paulo, v.13, supl. 1, p.38-40, 2004.

ANDERSON, M. L.; REYNOLDS, J. P.; ROWE, J. D.; SVERLOW, K. W.; PACKHAM, A. E.; BARR, B. C; CONRAD, P. A. Evidence of vertical transmission of Neospora sp. Infection in dairy cattle. Journal of The American Veterinary Medical Association, Schaumburg, v. 210, n. 8, p.1169-1172, 1997.

ANDREOTTI, R. Neosporose: um possível problema reprodutivo para o rebanho bovino. Campo Grande: EMBRAPA Gado de Corte, 2001. 14p. (Embrapa Gado de Corte. Documentos, 104).

ANDREOTTI, R.; LOCATELLI-DITTRICH, R.; SOCCO, V. T.; PAIVA, F. Diagnóstico e controle da neosporose em bovinos. Campo Grande: EMBRAPA Gado de Corte, 2003. 51p. (Embrapa Gado de Corte. Documentos, 136). 
BAILlARGEON, P.; FECTEAU, G.; PARÉ, J.; LAMOTHE, P.; SAUVEÉ, R. Evaluation of the embryo transfer producere proposed by the International Embryo Transfer Society as a method of controlling vertical transmission of Neospora caninum. Journal of the American Veterinary Medical Association, Schaumburg, v. 218, n. 11, p. 1803-1806, 2001.

BARAJAS-ROJAS, J. A.; MAPES, G.; YAÑEZ, I.; MORALES, E.; LASTRA G. Eficácia de uma vacina contra Neospora caninum em condições de campo no México. [online]. Disponível em: http://www.abspecplan.com.br/upload/library/Eficacia_vacina_contra_Neospora_caninum.pdf . Acesso em: 17 dez. 2012.

BARR, B. C. Question: What is neosporosis? Veterinary Exchange, Princeton, v.20, n.11, p.4, 1998.

BASZLER, T. V.; LAWRENCE, J. C.; MAUREENT, T. L.; MATHISON, B. Detection by PCR of Neospora caninum in fetal tissues from spontaneous bovine abortions. Journal of Clinical Microbiology, Washington, v. 37, n. 12, p. 4059-4064, 1999.

CAMILLO, G.; CADORE, G.; CEZAR, A. S.; TOSCAN, G.; BRÄUNIG, P.; SANGIONI, L. A.; VOGEL, F. S. F. Anticorpos anti-Neospora caninum em bovinos de leite do sudoeste do estado do Paraná. Arquivo Brasileiro de Medicina Veterinária e Zootecnia, Belo Horizonte, v. 62, n. 6, p. 1511-1513, 2010.

COLLERY, P. Neosporosis in domestic animals. Irish Veterinary Journal,Dublin, v.49, n. 3, p.152-156, 1996.

CORBELLINI, L. G.; SMITH, D. R.; PESCADOR, C. A.; SCHMITZ, M.; CORREA, A.; STEFFEN, D. J.; DRIEMEIER, D. Herd-level risk factors for Neospora caninum seroprevalence in dairy farms in southern Brazil. Preventive Veterinary Medicine, Amsterdam, v. 74, n. 2-3, p. 130-141, 2006.

COSTA, K. S.; SANTOS, S. L.; UZEDA, R. S.; PINHEIRO, A. M.; ALMEIDA, M. A.; ARAUJO, F. R.; MCALLISTER, M. M.; GONDIM, L. F. Chickens (Gallus domesticus) are natural intermediate hosts of Neospora caninum. International Journal for Parasitology, Oxford, v. 38, n. 2, p. $157-159,2008$.

DAVISON, H. C.; FRENCH, N. P.; ANDTREES, A. J. Herd-specific and age-specific seroprevalence of Neospora caninum in 14 British dairy herds. Veterinary Record, London, v. 144, n. 20, p. 547-550, 1999.

DE MEERSCHMAN, F.; RETTIGNER, C.; FOCANT, C.; BOREUX, R.; PINSET, C.; LECLIPTEUX, T.; LOSSON, B. Use of a serum-free medium to produce in vitro Neospora caninum and Toxoplasma gondii tachyzoites on Vero cells. Veterinary Research, Paris, v. 33, n. 2, p. 159-168, 2002.

DUBEY, J. P.; CARPENTER, J. L.; SPEER, C. A.; TOPPER, M. J.; UGGLA, A. Newly recognized fatal protozoan disease of dogs. Journal of the American Veterinary Medical Association, Schaumburg, v. 192, n. 9, p. 1269-1285, 1988.

DUBEY, J. P.; LINDSAY, D. S. A review of Neospora caninum and neosporosis. Veterinary Parasitology, Amsterdam, v.67, n. 1-2, p.1-59, 1996.

DUBEY, J. P. Neosporosis in cattle: biology and economic impact. Journal of the American Veterinary Medicine Association, Schaumburg, v. 214, n. 8, p. 1160-1163, 1999a.

DUBEY, J. P. Recent advances in Neospora and neosporosis. Veterinary Parasitology, Amsterdam, v. 84, n. 3-4, p.349-367, 1999b. 
DUBEY, J. P. Review of Neospora caninum and neosporosis in animals. Journal of Parasitology, Lawrence, v.41, n.1, p.1-16, 2003.

DUBEY, J. P.; BUXTON, D.; WOUDA, W. Pathogenesis of Bovine Neosporosis. Journal of Comparative Pathology, Edinburgh, v. 134, n. 4, p. 267-289, 2006.

FERRE, I.; GARCiA, A. G.; COLLANTES-FERNÁNDEZ, E.; PÉREZ, F. J.;ORTEGA-MORA, L. M. Diagnostico de La infección y del aborto causado por Neospora caninum em los bovinos. Produccion-Animal, Espanha, v.190, n. 92, p. 52-62, 2003.

FERREIRA, I. S. Neosporose bovina. 2000. 33 f. Monografia, Departamento de Medicina Veterinária, Universidade Federal de Lavras.

FERROGLIO, E.; PASINO, M.; ROMANO, A.; GRANDE, D.; PREGEL, P.; TRISCIUOGLIO, A. Evidence of Neospora caninum DNA in wild rodents. Veterinary Parasitology, Amsterdam, $v$. 148, n. 3-4, p. 346-349, 2007.

FORTUNATO, M.; GUEREIRO, D. S.; STILWELL, G. Neospora caninum como causa de aborto bovino em explorações leiteiras. Revista Vaca Leiteira, Lisboa, v. 18, n. 111, p. 64-68, 2010.

GONDIM, L. F. P.; SARTOR, I. F.; HARITANI, M. Neospora caninum infection in na aborted bovine foetus in Brazil. New Zealand Veterinary Journal, Wellington, v.47, n. 35, p.35, 1999.

GONDIM, L. F. P. Neospora caninum in wildilife. Trends in Parasitology, Oxford, v. 22, n. 6, p. 247-252, 2006.

GONDIM, L. F. P. Novos desafios para o controle da neosporose. In: XV Congresso Brasileiro de Parasitologia Veterinária, 15, 2008, Curitiba. Anais eletrônicos....[online]. Curitiba: 2008, p. $10 . \quad$ Disponível em: http://cnia.inta.gov.ar/helminto/Congreso\%20Brasil\%202008/NOVOS\%20DESAFIOS\%20CON TROLE\%20NEOSPOROSE.pdf

GONDIM, L. F.; LINDSAY, D. S.; MCALLISTER, M. M. Canine and Bovine Neospora caninum Control Sera Examined for Cross-Reactivity Using Neospora caninum and Neospora hughesi Indirect Fluorescent Antibody Tests. Journal of Parasitology, Lawrence, v. 95, n. 1, p. 8688, 2009.

GUIMARÃES JÚNIOR, J. S.; ROMANELLI, P. R. Neosporose em animais domésticos. Semina, Londrina, v. 27, n. 4, p. 665-678, 2006.

GUIMARÃES, A. M. Neosporose bovina. In: Doenças transmissíveis na Reprodução de Bovinos. UFLA/FAEPE: Lavras, 2007, 33p.

HAERDI, C.; HAESSIG, M.; SAGER, H.; GREIF, G.; STAUBLI, D.; B. GOTTSTEIN. Humoral immune reaction of newborn calves congenitally infected with Neospora caninum and experimentally treated with toltrazuril. Parasitology Research, Berlin, v. 99, n. 5, p. 534$540,2006$.

HALL, C. A.; REICHEL, M. P.; ELLIS, J. T. Neospora abortions in dairy cattle: diagnosis, mode of transmission and control. Veterinary Parasitology, Amsterdam, v. 128, n. 3-4, p. 231241, 2005. 
HEMPHILL, A.; GOTTSTEIN, B. A European perspective on Neospora caninum. International Journal for Parasitology, Oxford, v. 30, n. 8, p. 877-924, 2000.

HEMPHILL, A.; FELLEISEN, R.; CONNOLLY, B.; GOTTSTEIN, B.; HENTRICH, B.; MULLER, N. Characterization of a cDNA-clone encoding Nc-p43, a major Neospora caninum tachyzoite surface protein. Parasitology, Riverdale, v. 115, n. 6, p. 581-590, 1997.

HUANG, C. C.; YANG, C. H.; WATANABE, Y.; LIAO, Y. K.; OOI, H. K. Finding of Neospora caninum in the wild brown rat (Rattus norvegicus). Veterinary Research, Les Ulis, v. 35, n.3 ,p. 283-290, 2004.

INNES, E. A.; WRIGHT, S.; BARTLEY, P.; MALEY, S.; MACALDOWIE, C.; ESTEBAN-REDONDO, I.; BUXTON, D. The hostparasite relationship in bovine neosporosis. Veterinary Immunology and Immunopathology, Amsterdam, v. 108, n. 1-2, p. 29-36, 2005.

JENKINS, M. C.; PARKER, C.; HILL, D.; PINCKNEY, R. D.; DYER, R.; DUBEY, J. P. Neospora caninum detected in feral rodents. Veterinary Parasitology, Amsterdam,v. 143 , n. 2 , p. 143: 161-165, 2007.

JONES, T.C.; HUNT, R.D.; KING, N.W. Patologia veterinária. 6 ed. São Paulo: Manole, 2000, $1415 \mathrm{p}$.

KRITZNER, S.; SAGER, H.; BLUM, J.; KREBBER, R.; GREIF, G.; GOTTSTEIN, B. 2002. An explorative study to assess the efficacy of Toltrazuril-sulfone (Ponazuril) in calves experimentally infected with Neospora caninum. Annals of Clinical Microbiology and Antimicrobials, London, v.1, n. 4, 2002.

MACALDOWIE, C.; MALEY, S.W.,WRIGHT, S.; BARTLEY, P.; ESTEBAN- REDONDO, I.; BUXTON, D.; INNES, E. Placental pathology associated with fetal death in cattle inoculated with Neospora caninum by two diferent routes in early pregnancy. Journal of Comparative Pathology, Edinburgh v. 131, n. 2-3, p. 142-156, 2004.

MALEY, S. W.; BUXTON, D.; RAE, A. G.; WRIGHT, S. E.; SCHOCK, A.; BARTLEY, P. M.; ESTEBAN-REDONDO, I.; SWALES, C.; HAMILTON, C. M.; SALES, J; INNES, E. A. The pathogenesis of neosporosis in pregnant cattle: inoculation at mid-gestation. Journal of Comparative Pathology, Edinburgh, v. 129, n. 2-3, p.186-195, 2003.

MATOS, R. B. Atividade moduladora de flavonoides sobre a infecção por Neospora caninum em culturas de células gliais [online]. 2008. 43 p. Dissertação (Pós-graduação em Ciência Animal) - Universidade Federal da Bahia, Salvador. Disponível em http://www.mevtropical.ufba.br/arquivos/dissertacoes/2008/MatosRB.pdf .

McAlLISTER, M. M.; DUBEY, J. P.; LINDSAY, D. S. Dogs are definitive hosts of Neospora caninum. The International Journal for Parasitology, Oxford, v.28, n. 9, p. 1473-1478, 1998.

MCALLISTER, M. M.; BJORKMAN, C.; ANDERSON-SPRECHER, R; ROGERS, D. G. Evidence of pointsource exposure to Neospora caninum and protective immunity in a herd of beef cows. Journal of the American Veterinary Medical Association, Schaumburg, v. 217, n. 6 , p. 881-887, 2000.

MELO, D. P. G.; CAETANO, A. S.; ORTEGA-MORA, L. M.; BASTOS, S. A.; BOAVENTURA, C. M. Prevalência de anticorpos anti-Neospora caninum em bovinos das microrregiões de Goiânia e Anápolis, Goiás, Brasil. Revista Brasileira de Parasitologia Veterinária, São Paulo, v. 15, n. 3, p. 105-109, 2006. 
MOSKWA, B.; PASTUSIAK, K.; BIEN, J.; CABAJ, W. The first detection of Neospora caninum DNA in the colostrum of infected cows. Parasitology Research, Berlin, v. 100, n. 3, p. 633636, 2007.

MUGRIDGE, N. B.; MORRISON, D. A.; HECKEROTH, A. R.; JONSON, A. M.; TENTER, A. M. Phylogenetic analysis based on full-length large subunit Ribosomal RNA sequence comparison reveals that Neospora caninum is more close related to Hammondia heydorni than to Toxoplasma gondii. International Journal for Parasitology, Oxford, v. 29, n. 10, p.15451556, 1999.

OGAWA, L. Estudo soroepidemiológico do Neospora caninum e Toxoplasma gondii em bovinos de pecuária leiteira da região norte do Estado do Paraná. Londrina, 2000, 54p. Tese de Mestrado, Departamento de Medicina Veterinária Preventiva, Universidade Estadual de Londrina.

OSBURN, B.I. Ontogeny of immune responses in cattle. In: Ruminant Immune System inHealth and Disease, Cambridge University Press: Cambridge, 1986, p. 252-260.

PARKINSON, T. Specific infectious diseases causing infertility and subfertility in cattle. In: Veterinary reproduction and obstetrics. 9 ed. London: Saunders Elsevier, 2009, p. 476516.

PAZ, G. F.; LEITE, R. C.; ROCHA, M. A. Associação entre sorologia para Neospora caninum e taxa de prenhez em vacas receptoras de embriões. Arquivo Brasileiro de Medicina Veterinária e Zootecnia, Belo Horizonte, v.59, n.5, p. 1323-1325, 2007.

RADOSTITS, O. M.; GAY, C. C.; BLOOD, D. C.; HINCHCLIFF, K. W. Doenças causadas pelos protozoários. In: Clínica Veterinária: um tratado de doenças de doenças dos bovinos, ovinos, suínos, caprinos e equinos. 9. ed. Rio de Janeiro: Guanabara Koogan, 2002, p.1174-1776.

RAGOZO, A. M. A.; PAULA, V. S. O.; SOUZA, S. L. P.; BERGAMASCHI, D. P.; GENNARI, S. M. Ocorrência de anticorpos anti-Neospora caninum em soros bovinos procedentes de seis Estados brasileiros. Revista Brasileira de Parasitologia Veterinária, São Paulo, v.12, n.1, p.33-37, 2003.

RODRIGUES, S. C.; LUCAS, C.; BORSUK, S.; HARTBLEN, C.; LEIVAS, L. F. P.; PINTO, L. S.; AIRES, B. M. E. Avaliação de vacinas recombinantes para o controle de Neospora caninum. In: VI Congresso de Iniciação Científica, Pelotas. Anais... Pelotas: Universidade Federal de Pelotas, 2009, n. 18, p. 1-4.

SLAPETA, J. R.; KOUDELA, B.; VOTYPKA, J.; MODRY, D.; HOREJS, R.; LUKES, J. Coprodiagnosis of Hammondia heydorni in dogs by PCR based amplification of ITS 1 rRNA: differentiation from morphologically indistinguishable oocysts of Neospora caninum. Veterinary Journal, London, v. 163, n. 2, p. 147-154, 2002.

SARTOR, I. F.; GARCIA FILHO, A.; VIANNA, L. C.; PITUCO, E. M.; DAL PAI, V.; SARTOR, R. Ocorrência de anticorpos anti-Neospora caninum em bovinos leiteiros e de corte da região de Presidente Prudente, SP. Arquivo do Instituto Biológico, São Paulo, v. 72, n. 4, p. 413-418, 2005.

SERRANO-MARTINEZ, E.; FERRE, I., MARTÍNEZ, A.; OSORO, K.; MATEOS-SANZ, A.; DELPOZO, I.; ADURIZ, G.; TAMARGO, C.; HIDALGO, C. O.; ORTEGA-MORA, L. M. Experimental neosporosis in bulls: parasite detection in semen and blood and specific antibody and interferon-gamma responses. Theriogenology, Stoneham, v. 67, n. 6, p. 1175-1184, 2007. 
STASKA, L. M.; MCGUIRE,T. C.; DAVIES, C. J.; LEWIN, H. A.; BAZLER, T.V. Neospora caninuminfected cattle develop parasite-specific CD4+ cytotoxic $T$ lymphocytes. Infection and Immunity, Washington, v. 71, n. 6, p. 3272-3279, 2003.

TAYLOR, M. A.; COOP, R. L.; WALL, R. L. Parasitologia Veterinária. 3. ed. Rio de Janeiro: Guanabara Koongan, 2010, 742p.

VOGEL, F. S. F. V.; ARENHART, S.; BAUERMANN, F. V. Anticorpos anti-Neospora caninum em bovinos, ovinos e bubalinos no Estado do Rio Grande do Sul. Ciência Rural, Santa Maria, v. 36, n.6, p.1948-1951, 2006.

WAPENAAR, W.; BARKEMA, H. W.; VANLEEUWEN, J. A.; MCCLURE, J. T.; O'HANDLEY, R. M.; KWOK, O. C. H.; THULLIEZ, P.; DUBEY, J. P.; JENKINS, M. C. Comparison of serological methods for the diagnosis of Neospora caninum infection in cattle. Veterinary Parasitology, Amsterdam, v. 143, n. 2, p. 166-173, 2007. 